\title{
Targeted Reactivation during Sleep Differentially Affects Negative Memories in Socially Anxious and Healthy Children and Adolescents
}

\author{
Sabine Groch, ${ }^{1}$ Andrea Preiss, ${ }^{2}$ Dana L. McMakin, ${ }^{5,6}$ Björn Rasch, ${ }^{7}$ CSusanne Walitza, ${ }^{2}$ Reto Huber, ${ }^{1,2 *}$ \\ and Ines Wilhelm ${ }^{1,3,4 *}$ \\ ${ }^{1}$ University Children's Hospital Zürich, ${ }^{2}$ Department of Child and Adolescent Psychiatry and Psychotherapy, Psychiatric Hospital, ${ }^{3}$ Department of \\ Psychiatry, Psychotherapy and Psychosomatics, and ${ }^{4}$ Department of Experimental Psychopathology and Psychotherapy, University of Zürich, 8032 Zürich, \\ Switzerland, ${ }^{5}$ Florida International University, Department of Psychology, Miami, Florida 33199, ${ }^{\circ}$ icklaus Children's Hospital, Department of Neurology, \\ Miami, Florida 33155, and 7University of Fribourg, Department of Psychology, 1701 Fribourg, Switzerland
}

Cognitive models propose a negative memory bias as one key factor contributing to the emergence and maintenance of social anxiety disorder (SAD). The long-term consolidation of memories relies on memory reactivations during sleep. We investigated in SAD patients and healthy controls the role of memory reactivations during sleep in the long-term consolidation of positive and negative information. Socially anxious and healthy children and adolescents learnt associations between pictures showing ambiguous situations and positive or negative words defining the situations' outcome. Half of the words were re-presented during postlearning sleep (i.e., they were cued). Recall of picture-word associations and subjective ratings of pleasantness and arousal in response to the pictures was tested for cued and uncued stimuli. In the morning after cueing, cueing facilitated retention of positive and negative memories equally well in SAD patients and healthy controls. One week later, cueing led to reduced ratings of pleasantness of negative information in SAD but not in healthy controls. Coincidental to these findings was more pronounced EEG theta activity over frontal, temporal and parietal regions in response to negative stimuli in SAD patients. Our findings suggest that the preferential abstraction of negative emotional information during sleep might represent one factor underlying the negative memory bias in SAD.

Key words: consolidation; memory; reactivation; sleep; social anxiety

\section{Significance Statement}

We aim to uncover mechanisms underlying the characteristic negative memory bias in social anxiety disorder (SAD). The formation of long-lasting memories - a process referred to as memory consolidation- depends on the reactivation of newly acquired memories during sleep. We demonstrated that experimentally induced memory reactivation during sleep renders long-term memories of negative experiences more negative in SAD patients but not in healthy controls. We also found in SAD patients that the reactivation of negative experiences coincided with more pronounced oscillatory theta activity. These results provide first evidence that memory reactivation during sleep might contribute to the negative memory bias in SAD.

\section{Introduction}

Social anxiety disorder (SAD) is one of the most common mental disorders with a lifetime prevalence of $5-13 \%$ of the general

Received June 14, 2016; revised Jan. 5, 2017; accepted Jan. 17, 2017.

Author contributions: A.P., D.L.M., B.R., S.W., R.H., and I.W. designed research; S.G., A.P., and I.W. performed research; S.G. and I.W. analyzed data; S.G., D.L.M., R.H., and I.W. wrote the paper.

This work was supported by the Swiss National Science Foundation (Nr. 320030_153387); the Deutsche Forschungsgemeinschaft (Wi 4059/1-1); the Jacobs Foundation; the Child Research Centre of the University Children's Hospital, Zürich; Forschungskredit of the University of Zürich (Grant no. NR FK-14-044); and the Clinical Research Priority Program Sleep and Health. We thank Stephanie Burnett-Heyes for helping with the study material, Ronald E. Dahl for his support with planning the experiment and discussing the data, and Thomas Schreiner for his support with data analyses. We also thank Aylin Yantaz and Sina Unseld for their help with data collection. population (Essau et al., 1999; Furmark, 2002). SAD typically emerges during early to late adolescence and $75 \%$ of anxious adults already met the criteria of an anxiety disorder during childhood and adolescence (Pollack et al., 1996; Beesdo et al., 2009). These findings clearly indicate that there is a great need to im-

The authors declare no competing financial interests

* R.H. and I.W. contributed equally to this work.

Correspondence should be addressed to Ines Wilhelm, University Children's Hospital Zürich, Steinwiesstrasse 75, 8032 Zürich, Switzerland. E-mail: ines.wilhelm@kispi.uzh.ch.

DOI:10.1523/JNEUROSCI.1912-16.2017

Copyright $\odot 2017$ the authors $\quad 0270-6474 / 17 / 372425-10 \$ 15.00 / 0$ 
prove our understanding of the etiology and course of social anxiety in youth.

Cognitive models propose that superior memory for negative experiences is one major factor contributing to the emergence and maintenance of anxiety disorders (Clark and Wells, 1995; Rapee and Heimberg, 1997). However, empirical research on memory biases in SAD reveals inconsistent results. That is, a few studies report a bias toward negative threat-related memories (Lundh and Ost, 1996; Foa et al., 2000; Coles and Heimberg, 2005) while others report either no bias (Cloitre et al., 1995) or a memory bias only for implicit but not explicit memories (MacLeod and McLaughlin, 1995; Becker et al., 1999). Because most of these studies tested retention performance only a few minutes after encoding, a limiting factor in these experiments might be the length of the retention interval. In fact, memory biases might develop over longer time periods, as all newly acquired memory traces are subject to consolidation processes that start after encoding and take at least hours to days (Dudai et al., 2015). In the process of long-term consolidation, newly acquired memories are assumed to be gradually integrated into neocortical networks of existing memories (McGaugh, 2000; Dudai, 2004). Importantly, the long-term consolidation of memories results not only in a stabilization of a memory trace but also incorporates transformation processes and can result in the extraction of gist information (Brainerd and Reyna, 2001; Winocur et al., 2010; Nadel et al., 2012; Inostroza and Born, 2013; i.e., the extraction of core information from experiences).

Sleep after learning critically benefits the consolidation of newly acquired neutral and emotional information during childhood, adolescence, and adulthood (Wilhelm et al., 2012; for review, see Rasch and Born, 2013). Besides promoting the mere stabilization of the newly acquired information, sleep has been shown to benefit the extraction of gist information (Fischer et al., 2006; Gómez et al., 2006; Payne et al., 2008; Durrant et al., 2011; Stickgold and Walker, 2013; Wilhelm et al., 2013). Sleepdependent consolidation of memories critically relies on the repeated reactivation of these memories (Rasch and Born, 2013). In humans, this has been demonstrated in a number of experiments using the method of context cueing. By re-exposing sleeping subjects to odors, words, or tones (i.e., cues) associated with newly learnt neutral or emotional memories, memories were reactivated and more readily recalled later (Rasch et al., 2007; Rudoy et al., 2009; Cairney et al., 2014; Groch et al., 2016). The beneficial effect of memory cueing during sleep is represented on the electrophysiological level by an increase in EEG oscillatory theta (5-8 $\mathrm{Hz}$ ) and spindle activity (10-15 Hz; Schreiner and Rasch, 2015; Schreiner et al., 2015; Lehmann et al., 2016b). In the present study, we investigated in SAD patients and healthy controls the impact of memory cueing during postlearning sleep on the consolidation of newly acquired positive and negative memories. We hypothesized that in SAD patients, cueing preferentially affects newly encoded negative experiences, especially when tested after long retention intervals.

\section{Materials and Methods}

Participants. Thirteen children and adolescents suffering from SAD (mean \pm SEM: $13.36 \pm 0.57$ years; eight females, five males) and 13 healthy age-matched children and adolescents (mean \pm SEM: $13.15 \pm$ 0.57 years; four females, nine males) participated in the study. Healthy participants were recruited via advertisements in schools and local newspapers and socially anxious participants were recruited at the Department of Child and Adolescent Psychiatry and Psychotherapy, University of Zurich, Switzerland. SAD patients met the criteria for a SAD according
Table 1. Participants' data

\begin{tabular}{lcc}
\hline & $\begin{array}{c}\text { Healthy controls } \\
\text { (mean } \pm \text { SEM) }\end{array}$ & SAD (mean \pm SEM) \\
\hline Age & $13.11 \pm 0.57$ years & $13.38 \pm 0.58$ years \\
IQ & $109.54 \pm 3.35$ & $113.81 \pm 3.52$ \\
SAD questionnaires & & \\
$\quad$ SASC-R-D Fear of Negative & $15.00 \pm 0.95$ & $24.31 \pm 2.88^{* *}$ \\
$\quad$ Evaluation & $18.62 \pm 1.12$ & $32.31 \pm 2.56^{* * *}$ \\
$\quad$ SASC-R-D SAD & $12.77 \pm 0.95$ & $28.58 \pm 2.47^{* * *}$ \\
$\quad$ SASC-R-D Fear of Negative & & \\
$\quad$ Evaluation/Parents & $16.23 \pm 1.30$ & $32.08 \pm 2.80^{* * *}$ \\
$\quad$ SASC-R-D SAD/Parents & $7.23 \pm 0.97$ & $26.38 \pm 3.90^{* * *}$ \\
$\quad$ Sozialphobie und Angstinventar & & \\
$\quad$ für Kinder & & $26.00 \pm 3.34$ \\
Depression interview: Children's & & \\
$\quad$ Depression Rating Scale-Revised & & \\
\hline
\end{tabular}

Statistical differences between groups are indicated $\left({ }^{* *} p<0.01 ;{ }^{* * *} p<0.001\right)$.

to the Diagnostic and Statistical Manual of Mental Disorders, Fifth Edition (American Psychiatric Association, 2013) after evaluation by an experienced child and adolescent psychiatrist. To confirm initial clinical diagnosis, a clinical interview was performed by a second experienced child and adolescent psychiatrist using the Mini-International Neuropsychiatric Interview (Sheehan et al., 1998). To exclude prevalent comorbidity of depression in these patients, the Children's Depression Rating ScaleRevised (Keller et al., 2011; Table 1) was performed. Symptoms of social anxiety were assessed in all participants using two questionnaires, the Sozialphobie und Angstinventar für Kinder (Melfsen et al., 2001) and the Social Anxiety Scale for Children Revised-Child and Parents Version (SASC-R-D; Melfsen and Florin, 1997; Table 1). One participant originally planned to be included in the group of healthy participants was assigned post hoc into the group of socially anxious participants because of high scores of social anxiety as indicated by the SASC-R-D ( $>2$ SDs above the group mean). Interviews with all participants and their parents, as well as questionnaires, ensured that the participants had no cognitive impairments, neurological or sleep disorders. Participants did not take any medication at the time of the experiment except for one patient who received a selective serotonin reuptake inhibitor. Note, that excluding this participant as well as the participant assigned post hoc to the SAD group and their age-matched controls did not change the main findings (i.e., cueing $\times$ group interaction in a $2 \times 2$ ANOVA of pleasantness ratings for negative stimuli in Test Session 2 as well as the respective post hoc $t$ test were both $p<0.05$ ). The ingestion of caffeine or alcohol was not allowed on experiment days. The intelligence quotient (IQ) was assessed (Wechsler Intelligence Scale for Children; Petermann and Petermann, 2011) in each participant. Only participants with an IQ between 85 and 135 were included in this experiment. Socially anxious patients did not differ from healthy controls with regard to IQ $(p>0.38$; Table 1$)$. All participants were asked for individual sleep habits (i.e., usual time to go to bed, time getting up, etc.) to schedule both nights in the sleep laboratory in accordance with their usual sleep habits. One participant from the group of healthy participants did not enter the sleep EEG analyses because of technical problems.

The study was approved by the local ethics committee. The parents of the participants gave written informed consent before their children's participation. Additionally, all children and adolescents provided verbal assent. All participants received a voucher for reimbursement of expenses.

Design and procedure. Please see Figure $1 A$ for an illustration of the design and procedure. Participants were adapted to polysomnographic recordings on a night preceding the experiment proper. Experimental and adaptation night in the sleep laboratory were separated by $\geq 1$ night at home to exclude possible effects of bad sleep quality in the adaptation night on sleep in the experimental night. In the experimental night, participants came to the sleep laboratory $\sim 2.5 \mathrm{~h}$ before participants' habitual bedtime. First, the electrode net was placed to record nocturnal sleep during the subsequent night. Thereafter, participants performed 
A Learning
Session

Test Session 1

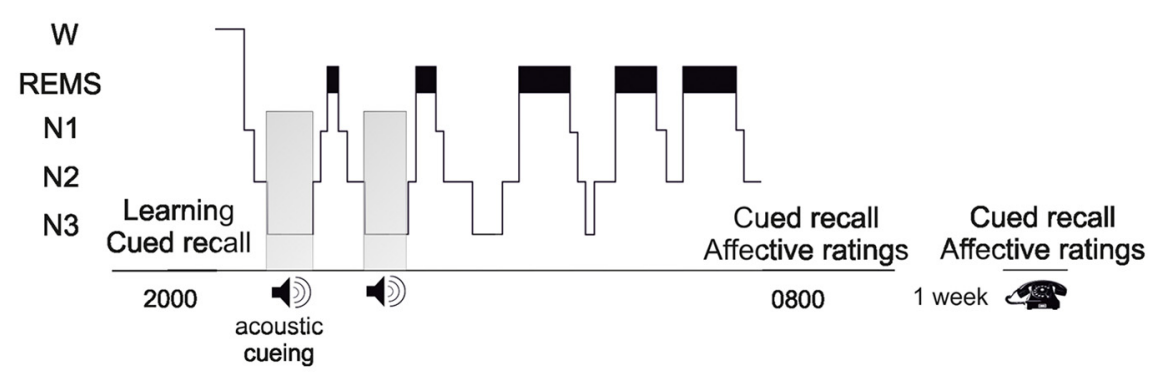

B

\section{Learning}

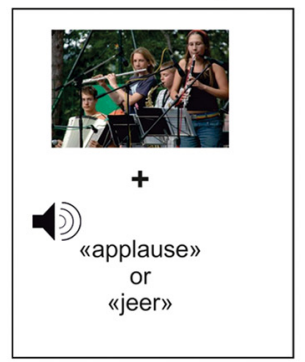

Cued recall

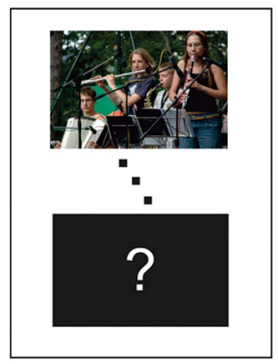

Affective ratings

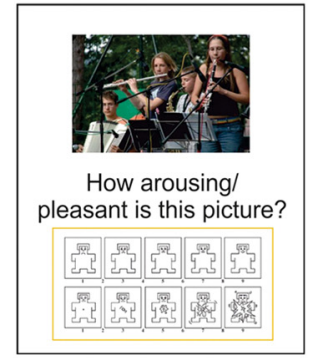

Figure 1. Experimental procedure and picture-word association task. $A$, After placement of the electrode net, participants completed a learning phase followed by immediate recall testing taking place between $\sim$ 8:00 p.m. and 10:00 P.M. A typical polysomnogram visualizes the proportion of sleep stages during the nocturnal retention interval [wake (W), NREM (Non-REM) sleep stages 1-3 (N1-N3), REM sleep (REMS)] and speakers indicate that acoustic cueing was performed during NREM sleep in the postlearning night. The next morning (Test Session 1) and 1 week later (Test Session 2), participants performed a cued memory recall test and subjectively rated the pictures for perceived pleasantness and arousal. $\boldsymbol{B}$, Learning the picture-word association task required participants to associate ambiguous pictures with acoustically presented positive or negative words that define the outcome of the pictures. Participants had to vividly imagine themselves in the situation shown on the picture. In the cued memory recall, pictures were shown again one after another and participants had to recall the associated word. In a separate run, participants were required to indicate the emotional affect elicited by each picture on a nine-point SAM rating scale on the dimensions of pleasantness and arousal.

the picture-word association task (Learning Session) and went to bed afterward. During nonrapid eye movement (NREM) sleep, half of the learnt words were played through a speaker placed behind the participants' head to stimulate the reactivation of respective picture-word associations. Testing started $\sim 45 \mathrm{~min}$ after waking up in the morning to avoid any modulating effect of sleep inertia on recall performance. This Test Session 1 as well as the Test Session 21 week later included the memory recall of picture-word associations and, in a second run, subjective ratings on the level of arousal and pleasantness of pictures on a nine-point self-assessment manikin (SAM; Bradley and Lang, 1994; see below for detailed description of the rating procedure).

Sleep EEG. Sleep in the experimental and the adaptation night was recorded using high-density sleep EEG (Electrical Geodesics Sensor Net for long-term monitoring, 128 channels, referenced to a vertex electrode) including electromyographic and electro-oculographic recordings. Data were sampled at $500 \mathrm{~Hz}(0.01-200 \mathrm{~Hz})$. Off-line, the EEG was bandpass filtered $(0.5-50 \mathrm{~Hz})$ and downsampled to $128 \mathrm{~Hz}$. The EEG was visually scored for sleep stages Wake, N1, N2, N3, and rapid eye movement (REM) sleep at frontal, central, and occipital electrodes (20 s epochs) based on American Academy of Sleep Medicine standard criteria (Iber et al., 2007). Socially anxious and healthy adolescents did not differ in any of the relevant sleep parameters (Table 2).

Memory cueing during sleep. During postlearning periods of NREM sleep, emotional words that had been paired with a picture during the learning phase were presented again by speaker (with a $55 \mathrm{~dB}$ sound pressure level). Half of the learnt words were cued; half were not. Half of the cued words were randomly and individually chosen from the group
Test Session 2 of words correctly remembered by the individual during the learning phase (i.e., hits), whereas the other half was taken from unknown words (i.e., misses). Half of the cued words were positive and half were negative. For example, given that a participant correctly remembered half of the 120 picture-word associations - with half of them negative and half of them positive-this would result in cueing of 15 positive and 15 negative hits and misses. Words were presented with an interstimulus interval of $6 \mathrm{~s}$ with a random jitter of $0-0.4 \mathrm{~s}$. Each of the chosen words was cued $\leq 12$ times (mean number of positive cues: SAD, 268.92 \pm 21.75; healthy controls, $223.92 \pm 15.92$; negative cues: $\mathrm{SAD}, 267.33 \pm 22.01$; healthy controls, $223.69 \pm 16.05$; all $p$ 's $>0.10)$. An experienced experimenter inspected the EEG in real time to determine sleep stages and to detect any indicator of an arousal. Word cueing was started when a participant had spent $>10 \mathrm{~min}$ in non-REM stage $\mathrm{N} 3$, and it was immediately stopped whenever any sign of an arousal, waking up, or any other change in sleep stages was observed by the experimenter. In line with previous studies showing beneficial effects of cueing on memory consolidation during non-REM sleep (Schreiner and Rasch, 2015; Schreiner et al., 2015; Lehmann et al., 2016b) but not during REM sleep (Lehmann et al., 2016b), memory cues were presented solely during non-REM sleep in this study.

Picture-word association task. The pictureword association task is based on previous studies that aimed to induce mental imagery using picture-word cues (Holmes et al., 2008; Pictet et al., 2011; Fig. 1B). This specific task was used because (1) mental imagery of picture-word associations has been shown to evoke strong emotional responses with this being attributed to the personal relevance of the memories (Holmes et al., 2008; Pictet et al., 2011) and (2) picture-word associations have been found to be sensitive for sleep-dependent processes of memory consolidation (Lehmann et al., 2016a) as well as for the beneficial effects of memory cueing during sleep (Lehmann et al., 2016b). The task includes a set of 120 (for participants $>12.4$ years old) or 102 (for participants $<12.4$ years old) ambiguous photographs of common everyday life objects and scenes. Pictures were paired with words chosen so that their combination with the picture (e.g., a picture showing a person acting in a play in front of an audience) either suggests a positive (half of the pictures; e.g., "applause") or a negative outcome of the scene shown on the picture (e.g., "jeer"). Before starting the learning procedure, all participants were instructed in an imagery generation task similar to those used in previous studies (Holmes et al., 2008) and underwent two practice trials. Participants were also instructed to memorize the picture-word associations because memory performance would be tested after learning and again after the retention interval. During learning, each of the picture-word associations was presented for $1500 \mathrm{~ms}$. A black screen then appeared for $3000 \mathrm{~ms}$, during which the participants were asked to shut their eyes and to generate mental images about the event. Thereafter, a 1000 ms beep informed participants to open their eyes and the next picture-word association was presented. Memory performance was tested for all picture-word associations in a recall procedure immediately after learning to assess baseline performance, and with the same procedure again the next morning and 1 week later. In these recall tests, all pictures were presented one after another in a random order for a duration of $1500 \mathrm{~ms}$ and the participants were required to recall the associated word (by speaking out loud the remembered word to the experimenter 
Table 2. Sleep parameters

\begin{tabular}{|c|c|c|c|c|c|c|}
\hline & \multicolumn{2}{|l|}{ Absolute time (in min) } & \multirow[b]{2}{*}{$p$ values } & \multicolumn{3}{|l|}{ Percentage of time (in \%) } \\
\hline & Healthy controls (mean \pm SEM) & SAD (mean $\pm S E M)$ & & Healthy controls (mean \pm SEM) & SAD (mean $\pm S E M)$ & $p$ values \\
\hline Sleep latency & $19.11 \pm 3.67$ & $15.36 \pm 3.53$ & 0.47 & & & \\
\hline $\begin{array}{l}\text { REM sleep latency } \\
\text { NREM sleep }\end{array}$ & $181.33 \pm 20.57$ & $151.77 \pm 11.36$ & 0.21 & & & \\
\hline N1 & $21.42 \pm 5.57$ & $24.80 \pm 4.81$ & 0.65 & $4.46 \pm 1.26$ & $4.63 \pm 0.82$ & 0.91 \\
\hline N2 & $241.22 \pm 5.88$ & $231.85 \pm 13.91$ & 0.55 & $48.53 \pm 1.45$ & $44.21 \pm 2.55$ & 0.16 \\
\hline N3 & $143.11 \pm 13.13$ & $166.23 \pm 15.49$ & 0.27 & $28.27 \pm 2.00$ & $31.47 \pm 2.60$ & 0.35 \\
\hline REM sleep & $94.44 \pm 6.43$ & $103.64 \pm 7.64$ & 0.37 & $18.74 \pm 1.02$ & $19.69 \pm 1.45$ & 0.60 \\
\hline Total sleep time & $500.19 \pm 14.32$ & $526.51 \pm 14.26$ & 0.21 & & & \\
\hline
\end{tabular}

who stood next to them and recorded memory performance). The time to generate a response was not limited. In Test Session 2, one week later, all participants were called by telephone by the experimenter and received via mail a slide show containing all pictures they had seen during the experiment. All words identical to the learnt word or that included the word stem of the learnt word were counted as correct (i.e., success and succeed). If a subject came up with more than one word, he or she would be prompted to choose just one. We calculated the relative difference between correctly recalled words before sleep and (1) in the morning after sleep (Test Session 1) and (2) 1 week later (Test Session 2) for cued and uncued picture-word associations as a measure of retention performance (i.e., $100 \%$ means the same amount of words being correctly recalled in both test sessions).

Ratings of pleasantness and arousal. To assess the two emotional dimensions [i.e., pleasantness and arousal (i.e., excitement)] we used the SAM rating system (Bradley and Lang, 1994). SAM is a nonverbal instrument for the assessment of emotional responses to a stimulus found to be suitable for this purpose in previous studies using International Affective Picture System pictures (Hamm et al., 1993; Wagner et al., 2002; Groch et al., 2013). After being tested on their memory performance for pictureword associations, participants were instructed that they will see each of the pictures again and that they had to rate spontaneously and quickly how they perceive the picture on the dimensions of pleasantness and arousal using a nine-point scale (pleasantness: 1, very unpleasant; 5, neutral; 9 , very pleasant; arousal: 1 , not arousing at all; 9 , very arousing). To do so, they had to use the buttons 1-9 of the computer keyboard in Test Session 1. In Test Session 2, they had to give their ratings verbally to the experimenter via telephone while viewing the pictures.

Analyses of power changes in response to cues. EEG signals were preprocessed using Brain Vision Analyzer 2.0 (Brain Products). Preprocessing included rereferencing of the raw EEG data to the average of the two mastoids and low-pass ( $30 \mathrm{~Hz}$, roll-off $24 \mathrm{~dB}$ per octave) and high-pass filtering $(0.1 \mathrm{~Hz}$, roll-off $12 \mathrm{~dB}$ per octave). EEG data were epoched into segments of $2 \mathrm{~s}$ before to $3 \mathrm{~s}$ after word onset. For each individual, segments were categorized in stimuli that were and stimuli that were not remembered in the test session in the morning (i.e., referred to as "laterremembered" and "later-forgotten" stimuli). Succeeding EEG oscillatory analyses were performed using the open-source Fieldtrip toolbox (Oostenveld et al., 2011) running on Matlab R2014a (MathWorks). Timefrequency analysis was computed for each trial by using a seven-cycle Morlet wavelet decomposition, ranging from 2 to $25 \mathrm{~Hz}$ in $0.5 \mathrm{~Hz}$ steps. A sliding window with a step size of $10 \mathrm{~ms}$ was applied across the entire length of the epochs. Single trials were normalized with respect to a prestimulus time window ranging from -1000 to $-100 \mathrm{~ms}$.

Statistical analyses. Statistical analysis of memory retention and subjective ratings was based on a $2 \times 2 \times 2 \times 2$ ANOVA including the repeated-measures factors valence (positive, negative), cueing (cued, uncued), and time (Test Session 1, Test Session 2) and the between-subjects factor group (socially anxious, healthy controls). In case of significant interactions in this initial analysis, $2 \times 2$ ANOVAs either including either the factors valence and cueing or valence and group were calculated. Post hoc comparisons were performed using Student's $t$ tests. The level of significance was set to $p \leq 0.05$.

Statistical analyses of the EEG data were performed with a nonparametric randomization test using cluster correction as implemented in
FieldTrip (Maris and Oostenveld, 2007). The cluster $\alpha$ was set to 0.025 and 500 randomizations were conducted for all tests. Clusters were considered significant at $p<0.05$ (two-sided).

\section{Results}

\section{Retention of picture-word associations}

In the evening before sleep, SAD patients and healthy controls learnt associations between pictures and positive and negative words equally well (main effect of valence: $F_{(1,24)}=1.66, p=0.20$ in a 2 (valence) $\times 2$ (group) $\times 2$ (cueing) ANOVA). Retention rates in this learning session did not differ between $S A D$ patients and healthy controls (main effect of group and valence $X$ group interaction, both $p$ 's $=0.42$ ).

During postlearning sleep, half of the positive and half of the negative words associated with ambiguous pictures in the learning session were acoustically presented again (cued associations), whereas the other half were not presented (uncued associations). We analyzed whether cueing substantially strengthened memory for picture-word associations in the morning after sleep (Test Session 1) and 1 week later (Test Session 2) in a 2 (time) $\times 2$ (cueing) $\times 2$ (valence) $\times 2$ (group) ANOVA. Importantly, the effect of cueing on memory recall was significantly modulated by the time of testing and the group of participants (time $\times$ group $\times$ cueing interaction: $\left.F_{(1,24)}=4.26 ; p=0.05\right)$. To disentangle the effect of cueing on memory recall at the different time points, we analyzed both test sessions separately in two 2 (cueing) $\times 2$ (group) $\times 2$ (valence) ANOVAs. In Test Session 1, both groups correctly remembered more picture-word associations that had been cued during postlearning sleep than those that had not been cued (main effect of cueing: $F_{(1,24)}=9.08, p=0.006$; Table 3). Importantly, the beneficial effect of memory cueing during sleep on retention performance did not differ between healthy and SAD children and adolescents (group $\times$ cueing interaction: $F_{(1,24)}=0.001, p=0.98$ ) and it was also not modulated by the valence of picture-word pairs (cueing $\times$ valence interaction: $\left.F_{(1,24)}=1.79, p=0.19\right)$. When tested 1 week later (Test Session $2)$, cued stimuli were no longer better remembered than uncued stimuli (main effect of cueing: $F_{(1,24)}=0.1, p=0.75$; interaction cueing $\times$ valence: $\left.F_{(1,24)}=0.34, p=0.57\right)$. At this time, there was a marginal significant interaction between the factors group and cueing $\left(F_{(1,24)}=4.09, p=0.055\right)$, suggesting that cueing differentially affects memory performance in SAD and healthy children and adolescents. However, further 2 (cueing) $\times 2$ (valence) ANOVAs separately for both groups did not reveal any impact of cueing on memory recall (SAD: main effect of cueing, $F_{(1,12)}=2.20$, $p=0.16$; cueing $\times$ valence interaction, $F_{(1,12)}=0.60, p=0.46$; healthy controls: main effect of cueing, $F_{(1,12)}=1.92, p=0.19$; cueing $\times$ valence interaction, $\left.F_{(1,12)}=0.003, p=0.96\right)$. 
Table 3. Memory retention and affective ratings

\begin{tabular}{|c|c|c|c|c|}
\hline & \multicolumn{2}{|l|}{ Healthy controls } & \multicolumn{2}{|l|}{ SAD } \\
\hline & Cued (mean \pm SEM) & Uncued (mean \pm SEM) & Cued (mean \pm SEM) & Uncued (mean \pm SEM) \\
\hline \multicolumn{5}{|l|}{ Encoding } \\
\hline Positive & \multicolumn{2}{|c|}{$71.22 \pm 3.17$} & \multicolumn{2}{|c|}{$72.66 \pm 2.79$} \\
\hline Negative & \multicolumn{2}{|c|}{$73.85 \pm 2.72$} & \multicolumn{2}{|c|}{$73.56 \pm 2.61$} \\
\hline \multicolumn{5}{|l|}{ Memory retention } \\
\hline \multicolumn{5}{|c|}{ Test Session 1} \\
\hline Positive & $105.93 \pm 2.57$ & $100.68 \pm 1.39$ & $103.16 \pm 1.60$ & $98.48 \pm 2.15$ \\
\hline Negative & $100.55 \pm 1.42$ & $99.68 \pm 1.59$ & $101.96 \pm 2.24$ & $100.44 \pm 2.58$ \\
\hline \multicolumn{5}{|l|}{ Test Session 2} \\
\hline Positive & $86.37 \pm 3.94$ & $94.14 \pm 2.94$ & $83.55 \pm 4.55$ & $84.56 \pm 2.37$ \\
\hline Negative & $82.96 \pm 3.23$ & $87.92 \pm 3.57$ & $82.53 \pm 4.14$ & $76.94 \pm 3.88$ \\
\hline \multicolumn{5}{|l|}{ Arousal } \\
\hline \multicolumn{5}{|l|}{ Test Session 1} \\
\hline Positive & $2.57 \pm 0.31$ & $2.72 \pm 0.31$ & $2.78 \pm 0.37$ & $2.58 \pm 0.36$ \\
\hline Negative & $2.55 \pm 0.26$ & $2.78 \pm 0.27$ & $3.27 \pm 0.43$ & $3.42 \pm 0.42$ \\
\hline \multicolumn{5}{|l|}{ Test Session 2} \\
\hline Positive & $2.79 \pm 0.35$ & $2.82 \pm 0.34$ & $3.79 \pm 0.39$ & $3.66 \pm 0.36$ \\
\hline Negative & $2.76 \pm 0.34$ & $2.76 \pm 0.37$ & $3.81 \pm 0.36$ & $4.07 \pm 0.34$ \\
\hline \multicolumn{5}{|l|}{ Pleasantness } \\
\hline \multicolumn{5}{|l|}{ Test Session 1} \\
\hline Positive & $5.75 \pm 0.26$ & $5.66 \pm 0.28$ & $5.62 \pm 0.25$ & $5.67 \pm 0.19$ \\
\hline Negative & $5.08 \pm 0.26$ & $4.90 \pm 0.23$ & $4.77 \pm 0.20$ & $4.93 \pm 0.22$ \\
\hline \multicolumn{5}{|l|}{ Test Session 2} \\
\hline Positive & $5.80 \pm 0.26$ & $5.50 \pm 0.28$ & $5.30 \pm 0.24$ & $5.24 \pm 0.20$ \\
\hline Negative & $5.16 \pm 0.30$ & $5.11 \pm 0.26$ & $4.70 \pm 0.14$ & $5.05 \pm 0.18$ \\
\hline
\end{tabular}

Memory retention is given in percent relative to memory performance in the Learning Session. Subjective emotional arousal and pleasantness are assessed using a nine-point scale (arousal: 1, not arousing at all; 9 , very arousing; pleasantness: 1 , very unpleasant; 5 , neutral; 9 , very pleasant).

\section{Subjective ratings of pleasantness of pictures}

In a next step, we analyzed whether cueing modulates the subjectively rated pleasantness of pictures. A 2 (time) $\times 2$ (cueing) $\times 2$ (valence) $\times 2$ (group) ANOVA revealed that cueing substantially affects pleasantness with this being modulated by the group of participants (group $\times$ cueing interaction, $F_{(1,24)}=5.66, p=$ $0.026)$ as well as by the time of testing and the valence of stimuli (cueing $\times$ valence $\times$ time interaction: $F_{(1,24)}=5.15 ; p=0.033$, Table 3). To further elucidate this complex interaction between the different factors, we again analyzed the two test sessions separately in two 2 (cueing) $\times 2$ (group) $\times 2$ (valence) ANOVAs. The valence of words modulated later ratings of pleasantness of the associated pictures in both test sessions (main effect of valence, both $\left.p^{\prime} s=0.001\right)$. These results indicate that our experimental manipulation (i.e., to disambiguate pictures by associating a positive or a negative word) was successful insofar as those pictures associated with a positive word were rated as being more pleasant than those pictures associated with a negative word. Subjectively rated pleasantness was neither affected by cueing nor by the mental health of participants in the morning after cueing (all main effects and interactions, $p>0.11$; Fig. $2 A$; note that Fig. 2 depicts the difference of pleasantness and arousal ratings between cued and uncued items and results from subtracting the mean values for cued and uncued items that can be seen in Table 3). Importantly, 1 week later (Test Session 2), cueing substantially modulated ratings of pleasantness in accordance with the valence of the associated word (cueing $\times$ valence interaction, $F_{(1,24)}=8.00, p=0.009$; Fig. $2 A$ ). Separate 2 (cueing) $\times 2$ (group) ANOVAs for positive and negative stimuli revealed a significant effect of cueing on rated pleasantness of positive stimuli (main effect of cueing: $F_{(1,24)}=5.83, p=0.024$ ). The effect of cueing did not significantly differ between SAD and healthy participants (cueing $\times$ group interaction: $F_{(1,24)}=2.53, p=0.12$ ). Although this interaction did not reach significance, we calculated further post hoc analysis for exploratory reasons. These $t$ tests indicated that in healthy controls cueing significantly increased ratings of pleasantness for pictures previously associated with a positive word $\left(t_{(12)}=2.88, p=0.014\right.$; Fig. $\left.2 A\right)$ while this was not the case in SAD participants $\left(t_{(12)}=0.58, p<0.57\right)$. For negative stimuli, the effect of cueing on the rated pleasantness significantly differed between both participants' groups (cueing $\times$ group interaction: $\left.F_{(1,24)}=4.63, p=0.042\right)$. Post hoc $t$ tests revealed a significant effect of cueing in $\operatorname{SAD}\left(t_{(12)}=2.3, p=0.04\right.$; Fig. $2 A)$ but not in healthy participants $\left(t_{(12)}=0.53, p=0.60\right)$.

\section{Subjective ratings of arousal of pictures}

Memory cueing during postlearning periods of sleep significantly affected the arousal ratings of pictures and this was modulated by the time of testing and the group of participants (time $\times$ group $\times$ cueing interaction: $F_{(1,24)}=4.72 ; p=0.04$ in a 2 (time) $\times 2$ (cueing) $\times 2$ (valence) $\times 2$ (group) ANOVA). Further 2 (cueing) $\times 2$ (valence) $\times 2$ (group) ANOVAs were calculated for the two test sessions separately. In the morning after cueing (Test Session 1), the subjectively rated arousal of pictures was higher for those pictures associated with a negative word compared with the pictures associated with a positive word (main effect of valence: $F_{(1,24)}=8.50, p=0.008$; Table 3). However, at this time, this effect of valence was different between SAD patients and healthy controls as indicated by a significant interaction between the factors group and valence $\left(F_{(1,24)}=7.40, p=0.012\right)$. Two (cueing) $\times 2$ (valence) ANOVAs separately for both groups revealed that SAD patients but not healthy controls rated pictures previously associated with a negative word to be more arousing than those pictures associated with a positive word (main effect of valence in SAD: $F_{(1,12)}=10.18, p=0.008$; in healthy controls: $\left.F_{(1,12)}=0.04, p=0.83\right)$. One week later (Test Session 2), SAD participants, compared with healthy participants, rated positive and negative stimuli to be more arousing (main effect of group: $\left.F_{(1,24)}=4.53, p=0.044\right)$. In contrast to Test Session 1, in Test Session 2, arousal ratings no longer differed between positive and 
A

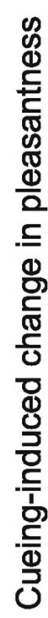

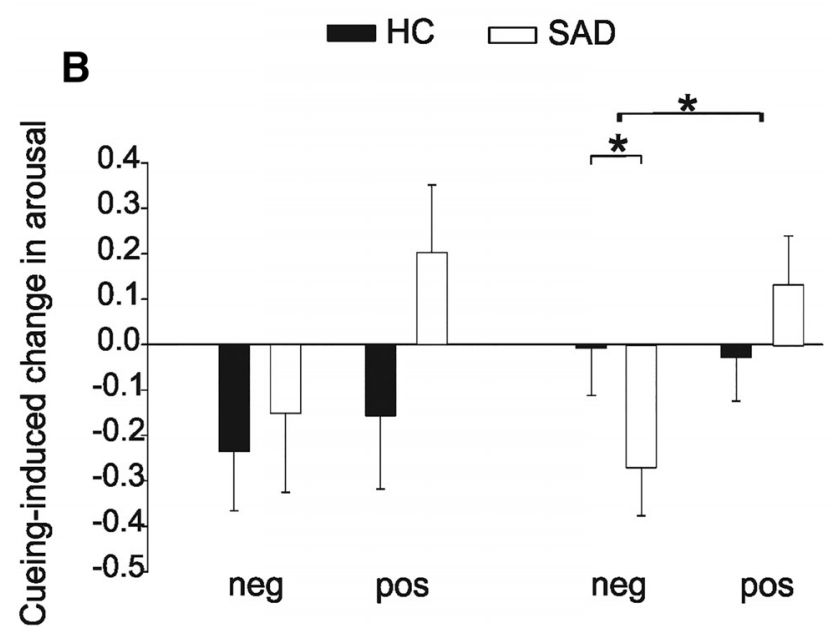

Figure 2. Cueing-induced changes in ratings of pleasantness $(\boldsymbol{A})$ and arousal $(\boldsymbol{B})$ in Test Session 1 and Test Session 2 in healthy (HC, black bars) and SAD participants (white bars). The cueing-induced change was calculated as the difference between pleasantness/arousal ratings of cued pictures and pictures that were not cued during sleep after learning. Thus, positive values indicate that cueing increased the subjectively rated pleasantness/arousal of pictures, whereas negative values indicate that cueing reduced the subjectively rated pleasantness/ arousal. $\boldsymbol{A}$, Cueing during postlearning sleep did not affect ratings of pleasantness in Test Session 1 but it significantly modulated ratings of pleasantness 1 week later. More specifically, memory cueing reduced the rated pleasantness of pictures previously associated with a negative word (neg) in SAD participants but not in healthy participants; and cueing increased the subjectively rated pleasantness of pictures previously associated with a positive word (pos) in healthy but not SAD participants. B, Cueing during postlearning sleep did also not affect arousal ratings in Test Session 1. One week later in Test Session 2, memory cueing reduced arousal ratings of pictures previously associated with a negative word in SAD participants but not in healthy participants.

negative stimuli (main effect of valence: $F_{(1,24)}=1.24, p=0.27$ ). However, 1 week after cueing (Test Session 2), arousal ratings were affected by cueing the respective information during postlearning sleep as indicated by the three-way valence $X$ cueing $X$ group interaction $\left(F_{(1,24)}=4.85, p=0.038\right)$. More specifically, cueing reduced the subjectively rated arousal of pictures that previously had been associated with a negative word in SAD but not in healthy participants (cued vs uncued: $\mathrm{SAD}, t_{(12)}=2.3, p=$ 0.04 ; healthy controls, $t_{(12)}=0.07, p=0.94$; Figure $2 B$ ). For pictures associated with a positive word, cueing neither modulated subjective arousal ratings in SAD patients nor in healthy controls (both p's $>0.12$; Fig. $2 B$ ).
Because previous studies indicate a beneficial effect of slowwave sleep on processes of memory consolidation (Marshall et al., 2006; Ngo et al., 2013), we correlated this sleep parameter with memory retention and ratings of pleasantness and arousal. Neither the absolute nor relative amount of slow-wave sleep correlated with the effect of cueing on any of these measures (all p's $>0.21$.

\section{Neuronal correlates of memory cueing during sleep}

To uncover possible electrophysiological correlates of the observed behavioral differences between SAD and healthy participants, the induced oscillatory responses to cues during postlearning periods of sleep were analyzed. We calculated the subsequent memory effect (SME; Paller and Wagner, 2002; i.e., the difference between cues associated with later-remembered stimuli and cues associated with later-forgotten stimuli for positive and negative stimuli). Based on previous findings demonstrating a causal role of theta in the successful reactivation of memories (Schreiner and Rasch, 2015; Schreiner et al., 2015; Lehmann et al., 2016b), these analyses were restricted to the theta frequency band (i.e., $5-8 \mathrm{~Hz}$ ) in a time window of 600-800 ms after cue onset. The SME for negative cues showed pronounced differences between SAD and healthy participants in the theta frequency range (Fig. $3 B$ ) while this was not the case for positive cues (Fig. 3A). More specifically, the SME differed significantly between both groups of participants in an electrode cluster spanning mainly the left frontal, temporal, and parietal cortices ( $p=0.002$, corrected for multiple comparisons; Fig. $3 C$ ). To uncover the origin of this significant interaction effect for negative stimuli, we contrasted theta activity in response to later-remembered and later-forgotten negative cues in both groups of participants separately. In SAD participants, later-remembered compared with later-forgotten negative cues induced higher theta activity in an electrode cluster over the left temporal and parietal cortices ( $p=0.009$, corrected for multiple comparisons; Fig. $3 D$ ). In healthy controls, comparing laterremembered with later-forgotten negative cues revealed reduced theta activity in a cluster located mainly over the left frontal and temporal cortices ( $p=0.012$, corrected for multiple comparisons; Fig. 3E).

\section{Discussion}

Here, we found in children and adolescents with SAD and in healthy controls that memory cueing during postlearning sleep benefits recall of positive and negative memories in the morning after cueing. One week later, cueing reduced subjectively rated pleasantness of pictures previously associated with a negative word in SAD but not in healthy controls. At the same time, the subjectively rated arousal of these negatively disambiguated pictures was reduced for cued compared with uncued negative stimuli in SAD but not healthy youth.

Our findings of increased retention performance for cued compared with uncued stimuli in the morning after cueing is in line with a number of previous studies reporting beneficial effects of cueing on the consolidation of neutral memories (Rasch et al., 2007; Rudoy et al., 2009; Schönauer et al., 2014; Groch et al., 2016). Moreover, our findings support recent empirical evidence indicating that cueing can facilitate the consolidation of emotional material as well (Cairney et al., 2014; Lehmann et al., 2016a). However, in our study, the ability to remember cued stimuli better than uncued stimuli was no longer evident 1 week later. In contrast, ratings of pleasantness were modulated by memory cueing not immediately after sleep but 1 week later. These different time scales might be related to the unique nature 
A

\section{SAD versus $\mathrm{HC}$ : positive cues}

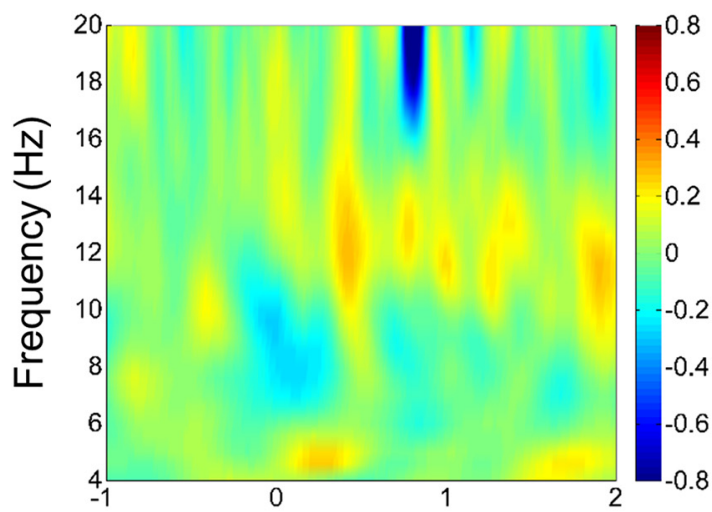

B SAD versus HC: negative cues

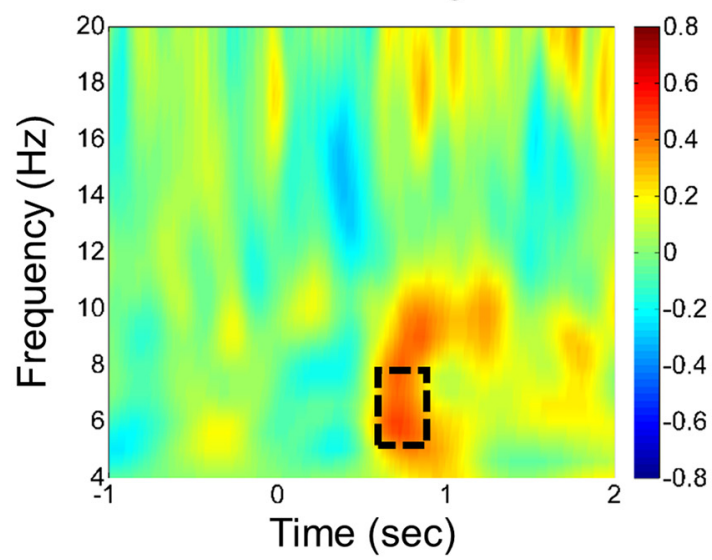

\section{Theta}
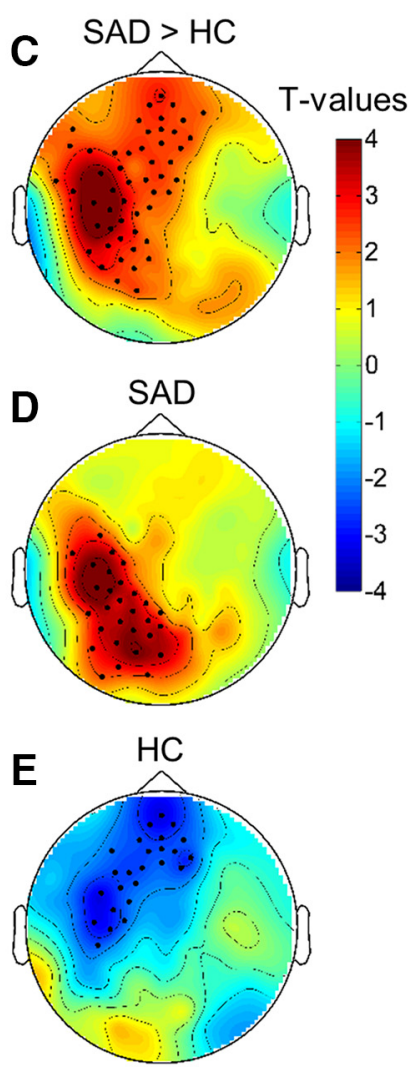

Figure 3. Time-frequency plots indicate the difference in the SME (later-remembered minus later-forgotten stimuli) between SAD and healthy participants $(\mathrm{HC})$ for positive and negative cues. $A$, The SME for positive cues did not differ between groups. $\boldsymbol{B}$, SAD participants compared with $\mathrm{HCS}$ showed a higher SME to negative cues in the theta frequency range (i.e., $5-8 \mathrm{~Hz}$; temporal electrode 41 is indicated here). C, The topographical distribution of the difference in the SME between SAD and HC participants is indicated for mean activity in the theta frequency band 600-800 ms after cue onset. The difference in the SME was most pronounced in a cluster over the left frontal, temporal, and parietal cortices ( $p=0.002$, corrected for multiple comparisons). $\boldsymbol{D}, \boldsymbol{E}$, Analyzing the SME for negative cues separately in SAD and HC participants revealed a positive cluster of electrodes mainly located over the left temporal and parietal cortices in $\operatorname{SAD}(\boldsymbol{D} ; p=0.01$, corrected for multiple comparisons) and a negative cluster over the left frontal and temporal cortices in HC participants $(\boldsymbol{E} ; p=0.01$, corrected for multiple comparisons). T values are indicated in $\boldsymbol{C}-\boldsymbol{E}$ and significant electrodes $(p<0.05)$ are highlighted.

of both measures of emotional memory processing. In our task, participants learnt associations between initially ambiguous pictures and words that had been chosen so that their combination suggests either a positive or a negative outcome of the picture. Importantly, during encoding, subjects had to form vivid mental images in response to the picture-word cues by seeing the scene through their own eyes as if they were actively involved, thereby including their own thoughts, emotions, and sensations. The exact word associated with the picture is rather a detail of this rich episode while ratings of pleasantness of the picture can be interpreted as a measure of gist in this context. This is well in line with previous assumptions indicating that pleasantness is one of the most fundamental gist representations of a stimulus (Reyna and Brainerd, 1998; Chen and Bargh, 1999; Rivers et al., 2008). Memory consolidation is a time-consuming process leading to fundamental changes in the neural representation, which are accompanied by significant changes in the nature of the memory (Brainerd and Reyna, 1991; Nadel and Moscovitch, 2001; Frankland and Bontempi, 2005; Winocur et al., 2010; Inostroza and Born, 2013). It is assumed that repeatedly reactivating hippocampal memory traces together with associated memory contents in the neocortex results over time in the integration of new memories in neocortical networks while the gist of the memory is extracted (Nadel et al., 2012; Inostroza and Born, 2013). Memory cueing in the postlearning night induces the reactivation of memories in the hippocampus (Rasch et al., 2007; Diekelmann et al., 2011) and this led the next morning to improved retention of picture-word associations. The immediate stabilization of hippocampal memory traces might have facilitated the long-lasting process of extracting gist information from these memory traces. Support for the notion that gist abstraction is relatively slow comes from studies investigating the effect of sleep on unbinding of an item from its associated context, which is another phenomenon resulting from the redistribution of memories from hippocampal to neocortical regions. A "decontextualization" of memories was found after 3 but not after 1 night of sleep (Deliens et al., 2013, 2014; Jurewicz et al., 2016). Moreover, Gais et al. (2007) found that sleep after learning novel words led to an increase in hippocampal activation during recall of the words $2 \mathrm{~d}$ later and to in an increase in mPFC activity after 6 months. Together, these findings indicate that the redistribution of memory traces from the hippocampus to neocortical networks that underlies the extraction of gist information might be initiated in the first night after learning but is observable at the behavioral level only after sleep over additional nights provide time for further endogenous reactivation.

Our findings suggest that cueing benefited the extraction of emotional gist information from negative stimuli in SAD patients but not in healthy controls. We hypothesize that these findings are related to different pre-existing associative knowledge networks in SAD patients and healthy controls. Information that matches preexisting memory networks is assumed to be integrated into neocortical memory networks more rapidly than nonmatching information (Tse et al., 2007; van Kesteren et al., 2012; Brod et al., 2013; Ghosh and Gilboa, 2014). SAD patients typically recall more negative autobiographical memories, negative self-defining memories, and early adverse social events (Morgan, 2010; Krans et al., 2014), indicating an elaborated network of negative memories in these patients. Activating this rich negative memory network by presenting associated memory cues might have facilitated the extraction of the emotional gist from the cued experiences. Our finding of greater theta activity in response to negative cues in SAD patients compared with healthy controls supports this idea since theta oscillatory activity was found to increase in response to cues that successfully induce memory reactivations (Schreiner and Rasch, 2015; Schreiner et al., 2015). 
In contrast to our findings in SAD patients, in healthy controls we found a reduction of theta activity in response to remembered compared with forgotten negative picture-word associations. Most of these associations might not have matched very well for these individuals (for example a picture showing a person acting in a play in front of an audience together with the word "jeer" might not match very well for a healthy participant, especially when he/she had to mentally imagine this scene on a field perspective). It can be speculated that more obvious associations between pictures and words need to be suppressed to learn less obvious associations. This might be reflected by decreased frontal theta for remembered compared with forgotten picture-word associations. This assumption is in line with a previous study showing reduced theta associated with beneficial memory formation specifically in a condition where the item and context do not match (Staudigl and Hanslmayr, 2013). Importantly, future studies should include measures of "congruency" to assess the extent of picture-word fit on an individual level and to relate this measure to theta activity in response to the cues.

Our findings of higher arousal ratings regardless of valence and cueing in SAD compared with healthy participants 1 week after encoding are in line with previous studies demonstrating that the subjectively rated arousal as well as the arousal-induced amygdala activation in response to emotional stimuli is higher in SAD patients compared with healthy controls (Brühl et al., 2014; Wieser and Moscovitch, 2015). Interestingly, memory cueing during sleep resulted in reduced arousal ratings of negative stimuli in SAD patients. This finding is consistent with a recent study in healthy adults reporting that cueing led to a reduction of arousal ratings (Rihm and Rasch, 2015). It also fits well with the notion that the consolidation of emotional memories not only results in the strengthening of memories (as reflected by a decrease in pleasantness ratings for negative stimuli in our study) but also in the reduction of their affective tone (Walker and van der Helm, 2009; Gujar et al., 2011; van der Helm et al., 2011).

We report three limitations in our experiment. First, because we only examined memory cueing during sleep, but not during wakefulness, we cannot conclude that the observed effect of memory cueing is specific to sleep. However, on the background of a number of studies showing no or even detrimental effects of cueing on memory consolidation during wakefulness (Rasch et al., 2007; Diekelmann et al., 2011; Schreiner and Rasch, 2015), we believe comparable effects after cueing during wakefulness to be unlikely. Second, participating in an experiment that includes cognitive testing as well as an overnight stay in a sleep laboratory is a huge challenge for SAD children and adolescents. On the one hand, this can explain the rather low number of participants who were in the end willing to participate while a much larger number of patients $(N>90)$ were informed about the experiment but did not agree to participate. On the other hand, this challenging situation might have resulted in a selection of SAD participants with rather low to moderate symptom severity. However, we do not believe that a possible selection of SAD patients with relatively low level of symptom severity undermines the interpretation of our findings. To the contrary, in more severely affected SAD patients we would expect even more pronounced differences. Third, both test sessions took place in different contexts. Test Session 1 was conducted in the sleep laboratory and participants were alone in the room while they rated the emotionality of pictures on the computer. In Test Session 2, participants were called by the experimenter and received via e-mail a slide show containing all previously seen pictures. They gave their ratings verbally to the experimenter. This situation might have induced higher gen- eral levels of arousal than in the sleep laboratory. Importantly, these differences cannot explain the observed cueing-induced changes in affective ratings as a higher general arousal should have equally affected cued and uncued stimuli. However, it could explain the higher arousal ratings of pictures in Test Session 2 compared with Test Session 1. According to the two-factor theory (Schachter and Singer, 1962), high arousal ratings might be caused by participants' misleadingly attributing the high arousal induced by the specific test context to the content of pictures.

Our findings have important implications for future research on normal and pathological processes of memory consolidation. First, to understand normal and pathological processes of memory consolidation, it is crucial to follow a memory trace for longer than a few minutes or hours as the memory trace is subject to long-lasting consolidation and transformation processes. Second, cueing during sleep is an elegant tool to further improve our understanding of the pathological processes of emotional memory processing by providing information about the sensitivity of a network to respond to memory cues. In this context, the role of pre-existing memories or schemas in the consolidation of new experiences in mental disorders is highly relevant and needs further investigation. Third, emotional memory biases are observable early in the development of SAD (i.e., during adolescence), underpinning the need to further investigate memory processes at this early developmental period.

\section{References}

American Psychiatric Association (2013) Diagnostic and statistical manual of mental disorders, fifth edition. Washington, DC: American Psychiatric Association.

Becker ES, Roth WT, Andrich M, Margraf J (1999) Explicit memory in anxiety disorders. J Abnorm Psychol 108:153-163. Medline

Beesdo K, Knappe S, Pine DS (2009) Anxiety and anxiety disorders in children and adolescents: developmental issues and implications for DSM-V. Psychiatr Clin North Am 32:483-524. CrossRef Medline

Bradley MM, Lang PJ (1994) Measuring emotion: the Self-Assessment Manikin and the Semantic Differential. J Behav Ther Exp Psychiatry 25: 49-59. Medline

Brainerd CJ, Reyna VF (1991) Fuzzy-trace theory and cognitive triage in memory development. Dev Psychol 27:351-369.

Brainerd CJ, Reyna VF (2001) Fuzzy-trace theory: dual processes in reasoning, memory, and cognitive neuroscience. Adv Child Dev Behav 28:41100. Medline

Brod G, Werkle-Bergner M, Shing YL (2013) The influence of prior knowledge on memory: a developmental cognitive neuroscience perspective. Front Behav Neurosci 7:139. CrossRef Medline

Brühl AB, Delsignore A, Komossa K, Weidt S (2014) Neuroimaging in social anxiety disorder-a meta-analytic review resulting in a new neurofunctional model. Neurosci Biobehav Rev 47:260-280. CrossRef Medline

Cairney SA, Durrant SJ, Hulleman J, Lewis PA (2014) Targeted memory reactivation during slow wave sleep facilitates emotional memory consolidation. Sleep 37:701-707, 707A. CrossRef Medline

Chen M, Bargh JA (1999) Consequences of automatic evaluation: immediate behavioral predispositions to approach or avoid the stimulus. Personal Soc Psychol Bull 25:215-224.

Clark DM, Wells A (1995) A cognitive model of social phobia. In: Social phobia: diagnosis, assessment, and treatment (Heimberg RG, Liebowitz MR, Hope DA, Schneier FR, eds.), pp 69-93. New York: Guilford.

Cloitre M, Cancienne J, Heimberg RG, Holt CS, Liebowitz M (1995) Memory bias does not generalize across anxiety disorders. Behav Res Ther 33:305-307. Medline

Coles ME, Heimberg RG (2005) Recognition bias for critical faces in social phobia: a replication and extension. Behav Res Ther 43:109-120. Medline

Deliens G, Gilson M, Schmitz R, Peigneux P (2013) Sleep unbinds memories from their emotional context. Cortex 49:2221-2228. CrossRef Medline

Diekelmann S, Büchel C, Born J, Rasch B (2011) Labile or stable: opposing consequences for memory when reactivated during waking and sleep. Nat Neurosci 14:381-386. CrossRef Medline 
Dudai Y (2004) The neurobiology of consolidations, or, how stable is the engram? Annu Rev Psychol 55:51-86. Medline

Dudai Y, Karni A, Born J (2015) The consolidation and transformation of memory. Neuron 88:20-32. CrossRef Medline

Durrant SJ, Taylor C, Cairney S, Lewis PA (2011) Sleep-dependent consolidation of statistical learning. Neuropsychologia 49:1322-1331. CrossRef Medline

Essau CA, Conradt J, Petermann F (1999) Frequency and comorbidity of social phobia and social fears in adolescents. Behav Res Ther 37:831-843. Medline

Fischer S, Drosopoulos S, Tsen J, Born J (2006) Implicit learning-explicit knowing: a role for sleep in memory system interaction. J Cogn Neurosci 18:311-319. Medline

Foa EB, Gilboa-Schechtman E, Amir N, Freshman M (2000) Memory bias in generalized social phobia: remembering negative emotional expressions. J Anxiety Disord 14:501-519. Medline

Frankland PW, Bontempi B (2005) The organization of recent and remote memories. Nat Rev Neurosci 6:119-130. Medline

Furmark T (2002) Social phobia: overview of community surveys. Acta Psychiatr Scand 105:84-93. Medline

Gais S, Albouy G, Boly M, Dang-Vu TT, Darsaud A, Desseilles M, Rauchs G, Schabus M, Sterpenich V, Vandewalle G, Maquet P, Peigneux P (2007) Sleep transforms the cerebral trace of declarative memories. Proc Natl Acad Sci U S A 104:18778-18783. CrossRef

Ghosh VE, Gilboa A (2014) What is a memory schema? A historical perspective on current neuroscience literature. Neuropsychologia 53:104-114. CrossRef Medline

Gómez RL, Bootzin RR, Nadel L (2006) Naps promote abstraction in language-learning infants. Psychol Sci 17:670-674. Medline

Groch S, Wilhelm I, Diekelmann S, Born J (2013) The role of REM sleep in the processing of emotional memories: evidence from behavior and event-related potentials. Neurobiol Learn Mem 99:1-9. CrossRef Medline

Groch S, McMakin D, Guggenbühl P, Rasch B, Huber R, Wilhelm I (2016) Memory cueing during sleep modifies the interpretation of ambiguous scenes in adolescents and adults. Dev Cogn Neurosci 17:10-18. CrossRef Medline

Gujar N, McDonald SA, Nishida M, Walker MP (2011) A role for REM sleep in recalibrating the sensitivity of the human brain to specific emotions. Cereb Cortex 21:115-123. CrossRef Medline

Hamm AO, Greenwald MK, Bradley MM, Lang PJ (1993) Emotional learning, hedonic change, and the startle probe. J Abnorm Psychol 102:453465. Medline

Holmes EA, Mathews A, Mackintosh B, Dalgleish T (2008) The causal effect of mental imagery on emotion assessed using picture-word cues. Emotion 8:395-409. CrossRef Medline

Iber C, Ancoli-Israel S, Chesson A, Quan SF (2007) The AASM manual for the scoring of sleep and associated events: rules, terminology and technical specifications (1st ed). Westchester, IL: American Academy of Sleep Medicine.

Inostroza M, Born J (2013) Sleep for preserving and transforming episodic memory. Annu Rev Neurosci 36:79-102. CrossRef Medline

Jurewicz K, Cordi MJ, Staudigl T, Rasch B (2016) No evidence for memory decontextualization across one night of sleep. Front Hum Neurosci 10:7. CrossRef Medline

Keller F, Grieb J, Ernst M, Spröber N, Fegert JM, Kölch M (2011) Children's Depression Rating Scale-Revised (CDRS-R): development of a German version and psychometric properties in a clinical sample. Z Kinder Jugendpsychiatr Psychother 39:179-185. Medline

Krans J, de Bree J, Bryant RA (2014) Autobiographical memory bias in social anxiety. Memory 22:890-897. CrossRef Medline

Lehmann M, Seifritz E, Rasch B (2016a) Sleep benefits emotional and neutral associative memories equally. Somnologie 20:47-53. CrossRef.

Lehmann M, Schreiner T, Seifritz E, Rasch B (2016b) Emotional arousal modulates oscillatory correlates of targeted memory reactivation during NREM, but not REM sleep. Sci Rep 6:39229. CrossRef Medline

Lundh LG, Ost LG (1996) Recognition bias for critical faces in social phobics. Behav Res Ther 34:787-794. Medline

MacLeod C, McLaughlin K (1995) Implicit and explicit memory bias in anxiety: a conceptual replication. Behav Res Ther 33:1-14. Medline

Maris E, Oostenveld R (2007) Nonparametric statistical testing of EEG- and MEG-data. J Neurosci Methods 164:177-190. Medline
Marshall L, Helgadóttir H, Mölle M, Born J (2006) Boosting slow oscillations during sleep potentiates memory. Nature 444:610-613. Medline

McGaugh JL (2000) Memory-a century of consolidation. Science 287: 248-251. Medline

Melfsen S, Florin I (1997) Ein Fragebogen zur Erfassung sozialer Angst bei Kindern (SASC-R-D). Kindheit und Entwicklung 6.

Melfsen S, Florin I, Warnke A (2001) SPAIK: Sozialphobie- und -angstinventar für Kinder. Göttingen, Germany: Hogrefe.

Morgan J (2010) Autobiographical memory biases in social anxiety. Clin Psychol Rev 30:288-297. CrossRef Medline

Nadel L, Moscovitch M (2001) The hippocampal complex and long-term memory revisited. Trends Cogn Sci 5:228-230. Medline

Nadel L, Hupbach A, Gomez R, Newman-Smith K (2012) Memory formation, consolidation and transformation. Neurosci Biobehav Rev 36:1640 1645. CrossRef Medline

Ngo HV, Martinetz T, Born J, Mölle M (2013) Auditory closed-loop stimulation of the sleep slow oscillation enhances memory. Neuron 78:545553. CrossRef Medline

Oostenveld R, Fries P, Maris E, Schoffelen JM (2011) FieldTrip: open source software for advanced analysis of MEG, EEG, and invasive electrophysiological data. Comput Intell Neurosci 2011:156869. CrossRef Medline

Paller KA, Wagner AD (2002) Observing the transformation of experience into memory. Trends Cogn Sci 6:93-102. Medline

Payne JD, Stickgold R, Swanberg K, Kensinger EA (2008) Sleep preferentially enhances memory for emotional components of scenes. Psychol Sci 19:781-788. CrossRef Medline

Petermann F, Petermann U (2011) Wechsler Intelligence Scale for Children (German Version, WISC-IV). Frankfurt: Pearson Assessment.

Pictet A, Coughtrey AE, Mathews A, Holmes EA (2011) Fishing for happiness: the effects of generating positive imagery on mood and behaviour. Behav Res Ther 49:885-891. CrossRef Medline

Pollack MH, Otto MW, Sabatino S, Majcher D, Worthington JJ, McArdle ET, Rosenbaum JF (1996) Relationship of childhood anxiety to adult panic disorder: correlates and influence on course. Am J Psychiatry 153:376381. Medline

Rapee RM, Heimberg RG (1997) A cognitive-behavioral model of anxiety in social phobia. Behav Res Ther 35:741-756. Medline

Rasch B, Born J (2013) About sleep's role in memory. Physiol Rev 93:681766. CrossRef Medline

Rasch B, Büchel C, Gais S, Born J (2007) Odor cues during slow-wave sleep prompt declarative memory consolidation. Science 315:1426-1429. Medline

Reyna VF, Brainerd CJ (1998) Fuzzy-trace theory and false memory: new frontiers. J Exp Child Psychol 71:194-209. Medline

Rihm JS, Rasch B (2015) Replay of conditioned stimuli during late REM and stage N2 sleep influences affective tone rather than emotional memory strength. Neurobiol Learn Mem 122:142-151. CrossRef Medline

Rivers SE, Reyna VF, Mills B (2008) Risk taking under the influence: a fuzzytrace theory of emotion in adolescence. Dev Rev 28:107-144. Medline

Rudoy JD, Voss JL, Westerberg CE, Paller KA (2009) Strengthening individual memories by reactivating them during sleep. Science 326:1079. CrossRef Medline

Schachter S, Singer JE (1962) Cognitive, social, and physiological determinants of emotional states. Psychol Rev 69:379-399. Medline

Schönauer M, Geisler T, Gais S (2014) Strengthening procedural memories by reactivation in sleep. J Cogn Neurosci 26:143-153. CrossRef Medline

Schreiner T, Rasch B (2015) Boosting vocabulary learning by verbal cueing during sleep. Cereb Cortex 25:4169-4179. CrossRef Medline

Schreiner T, Lehmann M, Rasch B (2015) Auditory feedback blocks memory benefits of cueing during sleep. Nat Commun 6:8729. CrossRef Medline

Sheehan DV, Lecrubier Y, Sheehan KH, Amorim P, Janavs J, Weiller E, Hergueta T, Baker R, Dunbar GC (1998) The Mini-International Neuropsychiatric Interview (M.I.N.I.): the development and validation of a structured diagnostic psychiatric interview for DSM-IV and ICD-10. J Clin Psychiatry 59:22-33;quiz 34-57. Medline

Staudigl T, Hanslmayr S (2013) Theta oscillations at encoding mediate the context-dependent nature of human episodic memory. Curr Biol 23: 1101-1106. CrossRef Medline

Stickgold R, Walker MP (2013) Sleep-dependent memory triage: evolving 
generalization through selective processing. Nat Neurosci 16:139-145. CrossRef Medline

Tse D, Langston RF, Kakeyama M, Bethus I, Spooner PA, Wood ER, Witter MP, Morris RG (2007) Schemas and memory consolidation. Science 316:76-82. Medline

van der Helm E, Yao J, Dutt S, Rao V, Saletin JM, Walker MP (2011) REM sleep depotentiates amygdala activity to previous emotional experiences. Curr Biol 21:2029-2032. Medline

van Kesteren MT, Ruiter DJ, Fernández G, Henson RN (2012) How schema and novelty augment memory formation. Trends Neurosci 35:211-219. CrossRef Medline

Wagner U, Fischer S, Born J (2002) Changes in emotional responses to aversive pictures across periods rich in slowwave sleep versus rapid eye movement sleep. Psychosom Med 64:627-634. Medline

Walker MP, van der Helm E (2009) Overnight therapy? The role of sleep in emotional brain processing. Psychol Bull 135:731-748. CrossRef Medline

Wieser MJ, Moscovitch DA (2015) The effect of affective context on visuocortical processing of neutral faces in social anxiety. Front Psychol 6:1824. CrossRef Medline

Wilhelm I, Prehn-Kristensen A, Born J (2012) Sleep-dependent memory consolidation-What can be learnt from children? Neurosci Biobehav Rev 36:1718-1728. CrossRef Medline

Wilhelm I, Rose M, Imhof KI, Rasch B, Büchel C, Born J (2013) The sleeping child outplays the adult's capacity to convert implicit into explicit knowledge. Nat Neurosci 16:391-393. CrossRef Medline

Winocur G, Moscovitch M, Bontempi B (2010) Memory formation and long-term retention in humans and animals: convergence toward a transformation account of hippocampal-neocortical interactions. Neuropsychologia 48:2339-2356. CrossRef Medline 